\title{
El ensayo latinoamericano, las metas normativas de desarrollo y la temática del reconocimiento
}

\author{
The Latin American essay, normative goals about recognition \\ development and thematic
}

\begin{abstract}
H. C. F. Mansilla
\section{Resumen}

El texto utiliza la temática del reconocimiento y los enfoques críticos en torno al romanticismo para comprender la compleja relación de las sociedades latinoamericanos con la modernidad occidental. Enfoques románticos son percibidos como una temprana crítica clarividente de las alienaciones modernas. En América Latina tendencias románticas han servido también para revalorizar el pasado y las tradiciones propias frente al peso cultural de la modernidad occidental. La ensayística latinoamericana es vista como una respuesta a la falta de reconocimiento de América Latina en el concierto de naciones. Pero algunas corrientes de la ensayística están bajo una influencia antiliberal y propenden a justificar regímenes populistas y autoritarios.
\end{abstract}

\section{Palabras clave}

América Latina, antiliberalismo, discriminación, ensayística, reconocimiento, romanticismo.

\section{Abstract}

The text is based on the recognition theme and on the critical analyses of romanticism in order to understand the complex relationship of Latin American societies with western modernity. Romantic conceptions are seen as an early and clairvoyant critique of modern alienations. In Latin America romantic tendencies have also served for revaluating the past and the own traditions in front of the cultural weight of western modernity. Latin American tradition of essays is perceived as an answer to Latin America's lack of recognition in the concert of nations. Some currents of the Latin American essays are, however, under antiliberal influence and are inclined to justify populist and authoritarian regimes.

\section{Key Words}

Antiliberalism, discrimination, essay, Latin America, recognition, romanticism.

Forma sugerida de citar: MANSILLA H. C. F. (2013). "El ensayo latinoamericano, las metas normativas de desarrollo y la temática del reconocimiento", en: Universitas, XI (18), enerojunio, pp. 51-78. Quito: Editorial Abya-Yala.

\footnotetext{
* Profesor (e), Universidad de Berlín. e-mail: hcf_mansilla@yahoo.com
} 


\section{La ensayística latinoamericana como respuesta a la falta de re- conocimiento}

Desde la primera mitad del siglo XIX se puede constatar en el Nuevo Mundo una rica tendencia intelectual consagrada a esbozar concepciones referidas a las preguntas por el destino y la vocación de sus sociedades. Aparte de la discusión primordial en torno a la libertad política y la prosperidad económica, otros temas más complejos ganaron paulatinamente en importancia, como la identidad nacional, la relación con las grandes potencias, la actitud adecuada frente al nuevo orden basado en la ciencia y la tecnología y la configuración de un futuro justo para sus pueblos. Estos temas recurrentes de la ensayística latinoamericana han estado concentrados, como es lo usual, en la esfera de la teoría y la retórica, pero hoy se puede aseverar que los grandes autores latinoamericanos contribuyeron desde un comienzo y eficazmente a percibir la complejidad de las cuestiones debatidas y a obtener una notable pluralidad de puntos de vista y programas de acción. ${ }^{1}$ La continuidad de este debate y la pluralidad de sus planteamientos $-\mathrm{y}$ de sus dudas- constituyen probablemente uno de los mejores legados culturales del Nuevo Mundo al saber universal.

La independencia de los estados latinoamericanos puede ser concebida como la intención expresa de los libertadores (y de los grupos dirigentes de la época) de dotar a estas tierras de un orden moderno, inspirado por los valores de la Ilustración y del racionalismo. Los autores latinoamericanos se percataron muy pronto de que las normativas ilustradas, a pesar de su calidad y prestigio, tenían una vigencia muy relativa en las sociedades europeas y en los países del Nuevo Mundo. Desde muy temprano la ensayística latinoamericana prestó atención a los vínculos tan intrincados que existen entre libertad política y justicia social, entre progreso económico y educación pública, entre consolidación nacional y unificación regional, y dio a conocer, mediante la variedad de sus

1 Cf. entre otros: Martin S. Stabb, América Latina en busca de una identidad. Modelos de ensayo ideológico hispanoamericano 1890-1960, Caracas: Monte Ávila 1969; Richard M. Morse, El espejo de Próspero. Un estudio de la dialéctica del Nuevo Mundo, México: Siglo XXI 1982; Leopoldo Zea, Filosofía de la historia americana, México: FCE 1978; José Joaquín Brunner, Los debates sobre la modernidad y el futuro de América Latina, en: Gonzalo Martner (comp.), Diseños para el cambio. Modelos socioculturales, Caracas: Nueva Sociedad / UNITAR 1987, pp. 110-115. 
programas, que no había una solución unitaria y simple para la multiplicidad de los desafíos históricos que enfrentaban las jóvenes naciones. Pese a la difusión de las concepciones liberales y a la autoridad de que gozaba el pensamiento racionalista, desde un comienzo los ensayistas llevaron a cabo una notable crítica del orden social reinante en Europa y de la ideología racionalista que lo acompaña, aunque, por supuesto, sin realizar un análisis detallado y empírico de aquello que posteriormente se conocerá como capitalismo. Esta crítica se concentra en aspectos culturales y religiosos, y exhibe una cierta similitud con el romanticismo del Viejo Mundo. Por otra parte hay que considerar una vigorosa opinión - de antigua data- que afirma que ni la Revolución Francesa ni el liberalismo británico tuvieron influencia sobre las corrientes que animaron la independencia de los países latinoamericanos, sino antiguas tradiciones culturales, como la religiosidad popular, el viejo autonomismo regional español y las ideas protodemocráticas derivadas del pensamiento municipalista de Castilla. ${ }^{2}$

Desde la primera mitad del siglo XIX la praxis política efectiva de los países latinoamericanos ha estado bastante alejada de los ideales racionalistas y liberales. Precisamente la consciencia de esta problemática, ardua, compleja y dolorosa, es la que ha motivado el nacimiento de las diversas líneas de la ensayística latinoamericana. La tensión entre la esfera del pensamiento y los programas, por un lado, y la vida prosaica del mundo cotidiano, por otro, ha originado en todos los modelos civilizatorios las reflexiones más fructíferas y profundas acerca de las dificultades de la convivencia razonable en el seno de las sociedades humanas y en torno a la función relativamente modesta de los esfuerzos teóricos. No hay duda, empero, de que los estados latinoamericanos - como pocos a escala mundial- han nacido con la intención expresa, típica de una modernidad precoz, de orientar sus actuaciones según los postulados de la Ilustración y el racionalismo, es decir, de acuerdo a las aspiraciones más elevadas de su época. Y no hay que olvidar que simultáneamente estas corrientes de pensamiento creyeron que en el Nuevo Mundo se podría edificar una opción

2 Cf. la recapitulación crítica de esta porción de la historia de las ideas en la hoy olvidada obra de Enrique de Gandía, Historia de América, en: H. G. Wells, Esquema de la historia universal, Buenos Aires: Anaconda 1948, t. II, pp. 435-843, especialmente pp. 584-611. 
civilizatoria genuinamente propia y ejemplar en un periodo histórico signado por la injusticia y la irracionalidad ${ }^{3}$

No se puede, obviamente, subsumir el variado y valioso tejido de la ensayística latinoamericana bajo un denominador único y simplificador, ya que la naturaleza misma del ensayo en cuanto género literario es plural, polémica y contradictoria, explorativa e hipotética. Se puede detectar, sin embargo, la recurrencia de algunos temas comunes a lo largo del tiempo y en la mayoría de los países: el anhelo de constituir una identidad social propia (Manfred Mols, 2011: 453-466), la recuperación provechosa de los legados culturales del pasado, la confrontación permanente con la civilización metropolitana del Norte, la adopción selectiva de inventos, pautas de comportamiento e instituciones provenientes de culturas externas y el percatarse de la relevancia de la ciencia y la tecnología para la configuración exitosa de la vida contemporánea, considerando que el desarrollo de ambas no ha sido justamente el fuerte de la evolución social latinoamericana.

Otro tema común es la búsqueda de reconocimiento en el plano de la comunidad internacional de países soberanos. En este punto se da hasta hoy una unanimidad de pareceres entre todas las corrientes de la ensayística latinoamericana. Desde un comienzo el anhelo de ser reconocidos como iguales por los otros estados soberanos en el concierto de las naciones ha sido de una importancia tal, que exonera a este popular anhelo de toda fundamentación intelectual. La persistencia y la intensidad de esta aspiración son comprensibles porque esa comunidad internacional se ha empeñado hasta el tiempo presente en tratar a los estados latinoamericanos como países de segunda categoría y, con algunas excepciones, a sus representantes intelectuales como figuras de escasa significación. La proclamada igualdad de naciones y personas no pasa de ser -en numerosos casos- un buen deseo, un postulado teórico de poca repercusión en el campo prosaico de la realidad y, por lo tanto, no debería ser tomado al pie de la letra por los pensadores y políticos latinoamericanos. Pero como el ser humano habitualmente no aprende de las experiencias ajenas, los estratos dirigentes

3 Testimonios de esa tendencia en: Miguel Jorrín / John D. Martz (comps.), LatinAmerican Political Thought and Ideology, Chapel Hill: North Carolina U. P. 1970, passim. 
del Nuevo Mundo han creído en el valor normativo y hasta supremo de esos postulados verbales y no siempre han considerado adecuadamente la distancia proverbial entre teoría y praxis en todos los tiempos y bajo todos los regímenes políticos. Por otra parte, hay que consignar el hecho repetitivo de que el cosmopolitismo liberal, que también presupone la igualdad de pueblos y personas, es a menudo un principio vacío. Con alguna seguridad se puede aseverar que no logra concitar emociones sociales relevantes. Y para ser reconocido por otros en igualdad de condiciones o, por lo menos, de posibilidades futuras, se requiere de empatía, es decir, de un mínimo de emoción. El orden moderno, tanto en su variante liberal como en otras de corte autoritario, no ha sido precisamente proclive a generar este tipo de sentimientos.

En esta constelación es comprensible que hayan surgido en América Latina varias respuestas de carácter a veces romántico con respecto a la modernidad y a la democracia liberal, y que estas respuestas se hayan mezclado inextricablemente con la problemática del reconocimiento a nivel internacional. La pluralidad de críticas y proyectos alternativos en el seno de la ensayística ha contribuido, por lo tanto, a buscar y encontrar nuevos horizontes teórico-heurísticos y a resaltar el valor de los elementos culturales y simbólicos con respecto a la evolución como totalidad - como es el caso del reconocimiento a nivel global-, lo que nos muestra que la ensayística desde un principio ha sostenido adecuadamente que los aspectos socio-económicos no son los únicos factores dignos de ser tenidos en cuenta.

\section{La ensayística antiliberal y la crítica romántica de la moderni- dad capitalista}

La línea más conocida e influyente de la ensayística latinoamericana es la que puede ser caracterizada como antiliberal (Loris Zanatta, 2008: 29-44). Este calificativo es inexacto e injusto para aprehender tendencias bastante disímiles en el pensamiento del Nuevo Mundo, y por ello es utilizado aquí provisionalmente como el mal menor a falta de una denominación más adecuada. Esta corriente de la ensayística latinoamericana puede ser tildada de conservadora, porque reproduce los elementos más usuales de la tradición católica y del ro- 
manticismo: el repudio del cosmopolitismo liberal, el rechazo del pluralismo ideológico y cultural, la indiferencia frente al Estado de derecho y a los valores democráticos pluralistas y la crítica, a veces muy acertada, del libre comercio y de la economía basada en la propiedad privada de los medios de producción. Numerosos autores de esta tendencia exhiben una propensión nacionalista y colectivista, un claro rechazo de posiciones antilaicas, una significativa "comprensión" de las tradiciones caudillistas y populistas en la esfera política y una inclinación provinciana y nacionalista, favorable a los usos y costumbres que vienen de muy atrás y de las "entrañas" de la tierra. Y todo esto puede combinarse relativamente bien con una propuesta modernizadora circunscrita a la esfera técnico-económica (Bohórquez, 2004: 35-49).

En la actualidad y bajo la fuerte influencia de teorías postmodernistas, estos ensayistas han adoptado, por supuesto, un ropaje intelectual a la moda del día, como son los cultural studies y afines (estudios subalternos y postcoloniales) de la academia norteamericana. En este contexto se puede percibir un renacimiento de posiciones teluristas, comunitaristas, indigenistas e indianistas, es decir, una nueva apreciación positiva de todos aquellos legados civilizatorios que aparentemente están opuestos a la tradición occidental capitalista, individualista y universalista. Muchos de estos ensayistas se adhieren al autoritarismo político y favorecen élites fuertes que "saben" guiar moralmente y hacer progresar a la nación respectiva. En una posición muy similar a la antigua Teoría de la Dependencia, son partidarios de la industrialización masiva bajo clases dirigentes nacionalistas (como ellos creen, por ejemplo, que han sido las élites modernizadoras japonesas). ${ }^{4}$

En el ámbito andino esta corriente favorece una revigorización de valores autóctonos, indigenistas y telúricos, llegando a rechazar las formas usuales -e ineludibles - de convivencia y cultura contemporáneas como el mestizaje (Morales Benítez, 2001: 301-315 - Sanjinés C, 2005). En esta constelación es indispensable mencionar, en passant, que la historia universal puede ser interpretada, por lo menos de manera parcial, como un proceso con innumerables fenómenos de mestizaje y aculturación. La historia significa también contacto

4 Cf. entre otros estudios críticos: Robert Packenham, The Dependency Movement: Scholarship and Politics in Development Studies, Cambridge: Harvard U. P. 1992. 
con lo foráneo y, a veces, comprensión de lo extraño. El mestizaje puede ser obviamente traumático, pero también enriquecedor (Bastide, 1973). Hasta se podría afirmar que las sociedades más exitosas han sido aquellas que han experimentado un número relativamente elevado de procesos de aculturación y que los individuos más aptos son los que tienen una multiplicidad de roles. El tratar de volver a una identidad previa a toda transculturación -como la precolombina, pues varios sectores políticos lo propugnan en el área andina- es, por lo tanto, un esfuerzo vano, anacrónico y hasta irracional: se puede pasar rápidamente de las reivindicaciones anti-imperialistas a las obsesiones nacionalistas y a los ensayos de limpieza étnica por la fuerza de las armas.

Los factores centrales de esta concepción fueron anticipados por el mexicano Lucas Alamán (1792-1853), quien puede ser calificado como el primer ensayista latinoamericano. Este aristócrata católico tuvo una considerable influencia sobre la vida política y cultural de su país en el siglo XIX. Era un gran admirador de la evolución industrial británica y simultáneamente un partidario de la cultura política y religiosa del hispanismo tradicional; 5 fue un propulsor enérgico de lo que ahora llamaríamos proyectos ambiciosos de desarrollo económico y, al mismo tiempo, un defensor decidido de la mano fuerte en el campo político-institucional. No tenía ninguna simpatía por la libertad de discusión y por los cuerpos deliberativos; detestaba toda manifestación de heterogeneidad estructural y percibía la solución de los problemas mexicanos en una sólida unión entre gobierno, ejército y clero (Alamán, 1963: 164-166). Salvando las distancias y actualizando los conceptos, Alamán parece un defensor del populismo autoritario a comienzos del siglo XXI. Por ejemplo: la elevada concepción que tenía Alamán del catolicismo de su época es muy diferente a la actual valoración positiva de la religiosidad popular. Pero en un punto central se da una coincidencia sintomática. Alamán, como numerosos pensadores de tendencia conservadora, creía en la función político-instrumental de la religiosidad popular que consiste en domeñar al pueblo y canalizar sus ímpetus mesiánico-

5 Cf. Salvador Méndez Reyes, El hispanismo de Lucas Alamán (1792-1853), Toluca: UAEM 1996; Guillermo Zermeño, La historia, una ciencia de Estado. Notas sobre la función social del historiador en México en el siglo XIX, en: Hugo Cancino (comp.). Los intelectuales latinoamericanos entre la modernidad y la tradición, siglos XIX y XX, Madrid / Frankfurt: Iberoamericana / Vervuert 2004, (nota 6), pp. 19-33, especialmente pp. 20-23. 
utópicos hacia metas inofensivas y bajo la dirección de las élites convencionales. Las posiciones barroco-románticas de los intelectuales izquierdistas de la actualidad ven en la religiosidad popular un modelo contemporáneo de solidaridad $^{6}$ masiva de los explotados y una expresión de la esperanza revolucionaria bajo ropaje tradicional. En ambos casos el llamado ethos barroco fomenta el colectivismo de las masas, el acatamiento de caudillos populistas y el rechazo del "cosmopolitismo liberal".?

A primera vista hay una gran distancia entre esta doctrina esencialmente conservadora y la ensayística posterior de corte nacionalista y socialista, pero analizando detenidamente la cuestión se advierte claramente las similitudes entre ambas posiciones. Por ello es conveniente dar un vistazo a la obra del argentino Manuel Ugarte (1875-1951), quien puede ser considerado como uno de los precursores más importantes de corrientes izquierdistas en el Nuevo Mundo y cuya obra experimenta ahora un renacimiento sintomático. Ugarte tuvo una notable influencia sobre la conformación de lo que podemos llamar la consciencia intelectual latinoamericana en torno a la identidad y el futuro del continente. Estuvo influido, como gran parte de su generación, por el uruguayo José Enrique Rodó (1871-1917) y su propuesta del arielismo, ${ }^{8}$ pero supo moldear una concepción propia con elementos nacionalistas y con un claro giro político izquierdista. Su idea de la "Patria Grande" (Ugarte, 1922), ha tenido desde entonces una enorme repercusión, pues combina la herencia antiliberal de vieja data, la malquerencia y el rencor con respecto a los Estados Unidos, la retórica general anti-imperialista y el redescubrimiento de lo positivo inmerso en las tradiciones propias. La compleja relación asimétrica con los Estados Unidos ocupa desde entonces un lugar predominante en la ensayística latinoamericana, que no lo poseía en la obra de los primeros autores como Lucas Alamán o Do-

6 Sobre la temática de la solidaridad cf. el interesante compendio de Kurt Bayertz (comp.), Solidarität. Begriff und Problem (Solidaridad. Concepto y problema), Frankfurt: Suhrkamp 1998, especialmente: Nicholas Capaldi, Was stimmt nicht mit der Solitarität? (¿Qué cosa no funciona con la solidaridad?), pp. 86-110.

7 Para una versión diferente en torno al ethos barroco cf. Stefan Gandler, Marxismo crítico en México: Adolfo Sánchez Vázquez y Bolívar Echeverría, México: FCE / UNAM 2007, pp. 391, 417-424.

8 José Enrique Rodó, Ariel [1900], México: Porrúa 1968, pp. 15-16, 26-37. Cf. Leopoldo Zea, Discurso desde la marginación y la barbarie, Barcelona: Anthropos 1988, p. 128. 
mingo Faustino Sarmiento. Esa asimetría está relacionada directamente con la falta de reconocimiento de los países latinoamericanos a nivel internacional. No hay duda de que Ugarte tuvo el mérito de estudiar las causas profundas de esa carencia fundamental, temática que evidentemente no fue incluida en los análisis de pensadores liberales como Sarmiento. La relevancia de Ugarte y de sus numerosos seguidores reside en el hecho de que ellos han percibido claramente esa asimetría, dando así los primeros e indispensables pasos para superarla.

La doctrina de Ugarte constituye, con las salvedades del caso, el programa intelectual imperante hasta hoy en los llamados círculos, movimientos y partidos "progresistas". Ugarte mismo tuvo simpatías por el peronismo -aunque se desilusionó prontamente-, pero no se preocupó por los aspectos autoritarios, paternalistas, colectivistas y antipluralistas que también distinguieron al peronismo y los regímenes nacionalistas de su tiempo. Siguiendo a Rodó, Ugarte rechazó, por otra parte, el utilitarismo vulgar y el materialismo grosero de la sociedad norteamericana, suponiendo que las naciones de origen latino representaban una alternativa ética y estéticamente más aceptable. Este programa, muy difundido hasta hoy, denota, sin embargo, un factor altamente problemático, que es la "reconciliación con el pasado hispánico" (Bergel, 2011: 152-167), la cual, en teoría y praxis, ha conllevado a ver en una luz positiva el legado político-institucional de esa herencia autoritaria y antiliberal.

La línea doctrinaria de Ugarte tiene en común con el romanticismo un carácter poco claro conceptualmente, pero muy proclive a sentimientos de gran arrastre popular. A En ambas corrientes les es propia una marcada propensión a un estilo retumbante y a una fraseología altisonante y belicosa, que encubren apenas la carencia de ideas claras sobre el futuro y acerca de las políticas públicas concretas que se pretende implementar. Esta incongruencia entre una retórica frondosa y una orfandad de planes realistas y específicos se advirtió claramente con ocasión de la guerra hispano-norteamericana de 1898. El debate intelectual y periodístico de entonces reavivó dos motivos de gran peso que han perdurado hasta hoy en el imaginario colectivo de extensos sectores poblacionales, motivos que -en diferentes dosis - prevalecen también en la producción académica, sobre todo en el área andina, México y América Central: (a) la crítica del imperialismo norteamericano y (b) la búsqueda de una identidad nacional propia e inconfundible, precisamente cuando las incursiones de la mo- 
dernidad occidental amenazan con barrer las diferencias identificatorias de los pueblos. Esta constelación es altamente favorable a ver los valores de orientación y las pautas recurrentes de comportamiento de las culturas precolombinas y de la época colonial española bajo una perspectiva parcializada que pasa por alto los aspectos autoritarios, antipluralistas y paternalistas de aquellos modelos civilizatorios. La retórica anti-imperialista ha cumplido "un inapreciable papel en la construcción de consensos y legitimidades" en la "cultura política nacional-popular, de consabido e inveterado arraigo en América Latina" (Bergel, 2011: 154).

En el último medio siglo estas ideas se han actualizado y diferenciado mediante los aportes de las ciencias sociales y económicas, ante todo bajo la influencia de las diversas escuelas sucesorias del marxismo. Ha perdido influencia la concepción romántica de vincular la pluma y el fusil (Gilman, 2003), es decir, la celebración entusiasta del nexo entre teoría progresista y praxis revolucionaria en la misma persona, como se creyó ver encarnado este vínculo en los luchadores de la Revolución Cubana. Paulatinamente ganó en relevancia la llamada "economización de agravios" (Marchesi, 2006: 135-160), la distancia creciente entre el desarrollo de los llamados centros metropolitanos (Europa Occidental y Estados Unidos) y el subdesarrollo de las naciones latinoamericanas, se debería principalmente a la acción perniciosa del imperialismo promovido por los países del Norte. La ensayística del Nuevo Mundo influida por los estudios económicos tiende a la exculpación de los factores endógenos por el atraso relativo del Tercer Mundo y a la percepción de las causas del subdesarrollo en la política imperialista de penetración y dominación ejercida por los centros metropolitanos.

Esta economización de la historiografía conlleva curiosos efectos en el campo político-institucional, que se derivan claramente de la tradición antiliberal latinoamericana. Los dos publicistas más conocidos de esta corriente, Jorge Abelardo Ramos y Eduardo Galeano, reivindican a regímenes dictatoriales, que aparentemente habrían defendido la "dignidad nacional" contra las intromisiones imperialistas. Esos gobiernos habrían tratado, al mismo tiempo, de inducir una estrategia "propia" de modernización basada en una industrialización "original", de acuerdo con las necesidades "reales" de las sociedades latinoamericanas. Es particularmente interesante y expresiva la apología que ambos 
autores han realizado de las dictaduras del doctor José Gaspar Rodríguez de Francia en Paraguay y de Juan Manuel de Rosas en Argentina, pues ambos caudillos edificaron en la primera mitad del siglo XIX regímenes particularmente despóticos, cuyos logros económicos — si es que realmente existieron- fueron modestísimos. ${ }^{9}$ Ambos autores atribuyen a estos sistemas profundamente autoritarios una serie de virtudes ético-políticas de amplio alcance popular y los enaltecen a la categoría de modelos precursores de la Revolución Cubana a causa de su presunta autonomía con respecto a los centros metropolitanos. Al estudiar el régimen del doctor Francia en el Paraguay, Galeano hace el abierto encomio del "Estado omnipotente, paternalista", que habría tomado a su cargo (y de modo muy original) "la tarea de organizar la nación y orientar sus recursos y su destino" (Galeano, 1975: 294). Galeano concede que durante este gobierno ocurrieron vulneraciones de los derechos humanos y que no existían "las libertades políticas y el derecho de oposición", pero aclara inmediatamente que sólo aquellos que acariciaban nostalgia por "los privilegios perdidos" podían sentir como negativa "la falta de democracia" (Galeano, 1975: 294-295).

Aquí es importante señalar un aspecto repetitivo y fundamental de la ensayística antiliberal. Un sistema político, considerado como altamente positivo y hasta paradigmático por su desempeño económico-técnico -o por la pretensión propagandística de serlo-, es eximido de toda crítica referida al campo políticoinstitucional: el presunto éxito en la industrialización o en la construcción de la autonomía económica con respecto a los centros metropolitanos hace aparecer como secundarias las preocupaciones por las libertades públicas y los derechos humanos. Esta trivialización de los elementos represivos en la esfera política es común a casi todas las tendencias nacionalistas y socialistas del pensamiento latinoamericano y contribuye a dar un nuevo lustre, esta vez progresista, al viejo principio de que el fin justifica los medios. ${ }^{10}$ Esta concepción es más frecuente

9 Jorge Abelardo Ramos, Introducción a la América criolla, Buenos Aires 1985, cap. III; Eduardo Galeano, Las venas abiertas de América Latina, Buenos Aires: Siglo XXI 1975, pp. 283-302.- Para una crítica temprana de estos enfoques cf. Carlos Rangel, El tercermundismo, Caracas: Monte Ávila 1982, pp. 150153.

10 Cf. Mario Benedetti, El desexilio y otras conjeturas, Madrid: El País 1984, p. 159: Habría que escribir una historia intencionadamente no objetiva de América Latina, que resalte las causas obviamente exógenas del subdesarrollo, pues el conocer y considerar los aspectos negativos de la cultura política sería caer en la "trampa de la objetividad". 
de lo que se cree. El mexicano Leopoldo Zea (1912-2004), el gran pensador de la autenticidad latinoamericana, analizó las complejas interrelaciones entre los centros metropolitanos y las periferias mundiales ("diálogos entre discursos"), y llegó a la conclusión de que una cierta apropiación de los modelos evolutivos de los centros sería inevitable; Zea abogó entonces por una adopción creativa y original de aquellos paradigmas de desarrollo. Pero en el despliegue de su argumentación, realizada en base a datos muy escasos de la realidad histórica, Zea consideró la obra modernizadora del zar Pedro I el Grande (1689-1725) como modélica porque instauró en Rusia un proceso acelerado de occidentalización e industrialización sin mayor consideración de los costes humanos del magno experimento social (Zea, 1988: 106-108).Como se sabe, la modernización parcial emprendida por este monarca contribuyó eficazmente a consolidar el despotismo habitual de aquella sociedad semi-asiática, empezando por el centralismo y terminando en el rechazo del Estado de derecho. ${ }^{11}$ Y precisamente esta constelación - la meta de la modernización técnico-económica justifica plenamente la represión en los terrenos político, institucional y cultural- es lo que atrae a Leopoldo Zea y a muchos intelectuales latinoamericanos como una solución enérgica y adecuada de un problema que se arrastra desde la independencia a comienzos del siglo XIX. Se supone ingenuamente que la envergadura y la intensidad de las reformas petrínicas en la Santa Rusia (u otras similares, como la Revolución Cubana (Ribeiro: 1986: 104-105)) ayudarán a fortalecer la dignidad nacional, es decir, a ganar el reconocimiento anhelado en el concierto de naciones, por un lado, y a revigorizar una cultura propia, no contaminada por el capitalismo uniformizador, por otro.

Para estas corrientes de la ensayística latinoamericana, marcadas por un evidente colectivismo, el Estado de derecho y el pluralismo ideológico resultan fenómenos de relevancia muy accesoria. Lo importante para ellas es en cambio el derecho del Estado de disponer sobre todos los recursos materiales y humanos en pro de las grandes metas de evolución histórica, lo que representa, en el fondo, la expectativa convencional del pensamiento tecnocrático: la preserva-

11 Para una visión crítica de esta temática cf. Umberto Melotti, Marx y el Tercer Mundo, Buenos Aires: Amorrortu 1974, pp. 125-130; Richard Pipes, Russland vor der Revolution. Staat und Gesellschaft im Zarenreich (Rusia antes de la revolución. Estado y sociedad bajo el imperio de los zares), Munich: dtv 1984, passim. 
ción de la rutinaria cultura política del autoritarismo y una visión meramente instrumental de la democracia. En toda América Latina existe hasta hoy en el imaginario popular la idea de que ambos factores contribuyen de modo enérgico al desarrollo acelerado. ${ }^{12}$

La dilatada influencia de los ensayistas latinoamericanos izquierdistas y nacionalistas sobre la opinión pública estriba en que ellos han sabido, mediante notables intuiciones, abordar algunos temas insoslayables para la conformación de la identidad colectiva y la consciencia intelectual de su época y proponer una síntesis entre el legado autoritario de vieja data y los logros técnico-económicos de la civilización industrial contemporánea. Esta simbiosis se percibe claramente en la obra del cubano Roberto Fernández Retamar (*1930), quien ha tratado de establecer una tradición "propia y auténtica" del pensamiento latinoamericano, definida "ex negativo" (ya no somos occidentales) y basada en los elementos antiliberales de la herencia hispano-católica y simultáneamente en el desempeño técnico-económico del llamado desarrollo acelerado. La teoría de Fernández Retamar intenta establecer un vínculo lógico y duradero entre la cultura política de la España colonial y el socialismo cubano de la actualidad, iluminado por la obra de José Martí, Fidel Castro y Ernesto Che Guevara, a quienes el autor atribuye considerables méritos filosóficos. (Fernández Retamar, 1976: 36-37). El autoritarismo del pasado aparece entonces como un conjunto de valores de orientación y pautas recurrentes de comportamiento que sería apropiado a la idiosincrasia popular de tiempos actuales; el antiliberalismo de la Revolución Cubana y su desdén por el Estado de derecho y el pluralismo ideológico se amoldarían perfectamente a las tradiciones colectivas de profunda raigambre histórica. Fernández Retamar relativiza los aspectos negativos de la colonia española mediante el cómodo argumento de que los otros modelos de colonización fueron igualmente malos o peores. La Leyenda Negra aparece como un mero libelo anti-español (Fernández Retamar, 1976: 28-41).

Finalmente hay que señalar que la ensayística antiliberal ha realizado a lo largo del siglo XX considerables esfuerzos para diferenciar el llamado nacionalismo progresista del nacionalismo reaccionario (Arregui, 1960). Esto es

12 Para el caso boliviano y con referencia al teórico más conocido de su izquierda nacionalista, cf. Fernando Molina, René Zavaleta. La etapa nacionalista, La Paz: Gente Común 2011, p. 75. 
esencial para una corriente de pensamiento que trata de rescatar elementos primordiales de tradiciones profundamente arraigadas en el pasado latinoamericano. Estas herencias culturales tienen su origen en la era precolombina y en la época colonial española y se distinguen, como se ha mencionado a lo largo de este texto, por el anticosmopolitismo, el antiliberalismo y, sobre todo, por una visión edulcorada de regímenes populistas y caudillistas de los siglos XIX y $\mathrm{XX}$, cuyo único mérito radica en esfuerzos modernizadores de corte autoritario y en manifestaciones verbales antinorteamericanas, de escaso efecto práctico, pero de gran visibilidad propagandística. Ahora se trata de demostrar que esos sistemas socio-políticos han sido, en el fondo, progresistas, diferentes de los regímenes reaccionarios, es decir, de aquellos favorables a los intereses de los Estados Unidos y del imperialismo británico.

Estas líneas de pensamiento estuvieron inspiradas por el revisionismo histórico en la Argentina a partir de aproximadamente 1930, que resultó ser fervientemente antiliberal y prohispanista, a menudo con elementos doctrinales propicios al catolicismo integrista. (En la actualidad esta última tendencia ha sido reemplazada por un fuerte impulso favorable al ethos barroco católico.) Ha sido ante todo una concepción difundida por pensadores proclives al peronismo y de procedencia conservadora, como el gran historiador y novelista Manuel Gálvez (1882-1962). La idea central es muy simple: el liberalismo habría distorsionado perversamente la historia argentina, la profunda, la auténtica, la nacional, es decir, la que no fue influida o contaminada por el universalismo y el racionalismo europeos. ${ }^{13}$ El genuino deber intelectual y público-político sería retornar a esa base sana de una mentalidad realmente propia, sentida y aceptada como tal por el grueso de la población y por los intelectuales progresistas. Es fácil comprender la inmensa popularidad de esta concepción central, que mediante regímenes populistas conoce un notable renacimiento en las primeras décadas del siglo XXI.

13 Cf. los estudios críticos: Maristella Svampa, El dilema argentino: civilización o barbarie. De Sarmiento al revisionismo peronista, Buenos Aires: El Cielo por Asalto 1994; Michael Goebel, Marxism and the Revision of Argentine History in the 1960s, en: Estudios Interdisciplinarios de América Latina y El Caribe. vol. 17. $\mathrm{N}^{\mathrm{o}} 1$. enero-junio de 2006, pp. 161-184, especialmente p. 163. 


\section{Dilemas centrales del pensamiento socio-político en América Latina}

La ensayística latinoamericana engloba muy diferentes corrientes ideológicas, lo que, como se ha dicho, constituye uno de sus aspectos más positivos y promisorios. Desde la primera mitad del siglo XIX las tendencias pro-occidentales han sido importantes, pues parecían encarnar el espíritu progresista de la época. Los pensadores adscritos a esta línea ideológica creían que la búsqueda de soluciones originales para el desarrollo del Nuevo Mundo era inútil, pues ya existía el paradigma evolutivo por excelencia: la civilización moderna, urbana, industrial, laica y moderadamente democrática, encarnada entonces por los países más adelantados de Europa Occidental (Francia y Gran Bretaña) y los Estados Unidos. Mediante la imitación de esos ejemplos se esperaba mejorar sustancialmente la importancia de los países latinoamericanos en el concierto de las naciones y alcanzar el reconocimiento internacional que el Nuevo Mundo merecía a escala planetaria.

Los dos primeros representantes de esta tendencia fueron los argentinos Juan Bautista Alberdi (1810-1884) y Domingo Faustino Sarmiento (1811-1888); su posición básica puede ser calificada como pro-europeísta y anti-indigenista. Alberdi sostenía que la inmigración europea era sinónimo de progreso y que la imitación del desarrollo británico, basado en la industria y el comercio, representaría "el gran medio de moralización" de los pueblos (Bautista Alberdi, 1979: 51-59). Para Sarmiento los factores adversos al progreso eran los caudillos federales del interior argentino, agentes y propagadores de la fatalidad de la historia y de la herencia hispano-católica. El legado cultural asociado a España fue visto por Sarmiento como anticuado, bárbaro e imprevisible (Sarmiento, 1845).

Para los integrantes de esta corriente en el siglo XIX, la tarea civilizadora era partir pragmáticamente de la única realidad entonces detectable, que eran las repúblicas iberoamericanas en su conformación momentánea, pues tanto los modelos institucionales indígenas como la concepción de una Patria Grande, que abarque todos los países latinoamericanos, representarían ideas utópicas, alejadas de las posibilidades reales del momento y del paradigma evolutivo modernizador de Europa Occidental. Contra las corrientes nacionalistas e indigenistas, estos pensadores creían que no existía un núcleo identificatorio de la 
nación, definible en términos esencialistas, que mereciera ser rescatado. Alberdi y Sarmiento reconocían la enorme brecha existente entre la realidad cotidiana de aquella época y el paradigma occidental, y aseveraban que la obligación de todo gobierno era reducir esa distancia educando al pueblo en el espíritu democrático de las instituciones modernas e impulsando el mérito y el talento individuales como factores privilegiados del desarrollo social, propugnando asimismo el fortalecimiento de una cultura política liberal-cosmopolita y afianzando el imperio de la ley y la vigencia de los derechos humanos.

Es evidente que estas corrientes pro-occidentales han descuidado la compleja problemática étnico-cultural, policlasista y plurilingüe de muchas sociedades latinoamericanas. Han cultivado, al mismo tiempo, una cierta ingenuidad que reaparece en el máximo exponente actual del pensamiento liberal, Mario Vargas Llosa (*1936), al suponer que la educación de las masas en un espíritu liberal, democrático e individualista iba a la larga a igualar las periferias mundiales con los centros metropolitanos y a generar un debilitamiento de las propensiones populistas de las sociedades latinoamericanas (R. Cristoffanini, 2004: 113-124). En la formulación de las metas normativas de evolución y en la configuración de los aspectos institucionales, los ensayistas liberales rechazaron conscientemente todo intento de originalidad y novedad y recomendaron para sus países la reproducción (eso sí: bien hecha) de aquellos sistemas de organización social y política que habían dado resultados más o menos razonables en las naciones del Norte.

En la actualidad la renovada vigencia del revisionismo histórico ha devaluado el peso y el alcance de las doctrinas liberales. Este fenómeno ha llevado paulatinamente, para citar un ejemplo elocuente, a que en la Argentina Sarmiento se convierta en un intelectual menor: ahora dilatados sectores sociales lo perciben como el admirador candoroso de la modernidad capitalista europea, el introductor de una forma subalterna de cultura capitalista y el presidente que hizo causa común con la oligarquía terrateniente. ${ }^{14}$

14 Cf. por ejemplo: José Luis de Diego, ¿Quién de nosotros escribirá El Facundo? Intelectuales y escritores en Argentina (1970-1986), La Plata: Ediciones al Margen 2001; Silvia Sigal, Intelectuales y poder en Argentina: la década del sesenta, Buenos Aires: Siglo XXI 2002. 
Como contraste a muchas aseveraciones de este texto, hay que mencionar la existencia de una corriente crítica en el seno de la ensayística latinoamericana. Esta tendencia comparte con los pensadores pro-occidentales una actitud distanciada con respecto al acervo cultural aborigen, a las tradiciones hispánico-católicas y a las prácticas nacionalistas y populistas. Esta línea se distingue, entre otras características, por una oposición matizada con respecto a los paradigmas occidentales y metropolitanos de evolución histórica. El ya nombrado José Enrique Rodó hizo una importante contribución a esta concepción mediante su rechazo ético y estético de la civilización industrial y comercial encarnada por los Estados Unidos (el predominio del número sobre la calidad). El representante más ilustre de la ensayística crítica es seguramente Octavio Paz (1914-1998), quien ha combinado una visión escéptica en torno a la modernidad y sus paradigmas con un análisis luminoso de los legados culturales y de las mentalidades colectivas, especialmente la mexicana. Lo que se denomina de manera imprecisa el carácter nacional de un pueblo es, según Paz, una identidad colectiva plural, cambiante y equívoca, pero con algunos rasgos distintivos que la hacen aparecer también como un muro construido para defender la comunidad nacional de un mundo externo reputado como peligroso y falaz y, al mismo tiempo, como una máscara que expresa necesidades y anhelos populares, pero que asimismo puede impedir el despliegue de consciencias individuales disidentes (Paz, 1950).

Paz llamó la atención acerca de tradiciones históricas que han sido positivas y promisorias en algunos campos (como las artes plásticas, la literatura y el logro de una solidaridad efectiva, no mediada burocráticamente), pero que han resultado autoritarias y antidemocráticas en el terreno político-institucional (Paz, 1976: 132-133). Paz criticó las estructuras altamente centralistas, jerárquicas y piramidales y la pervivencia de los caudillos en las civilizaciones precolombinas, en la era colonial ibérica y en el presente republicano; la enseñanza de la historia en las escuelas y la opinión pública alimentarían una visión edulcorada y embellecida - con claros elementos románticos- acerca de un pasado glorioso y exento de las alienaciones modernas. Precisamente esta perspectiva premeditadamente falsa de la historia evita un análisis crítico de la misma que pudiera tener consecuencias sociales y contribuye en cambio a perpetuar una mentalidad autoritaria. Uno de los mayores méritos de 
Octavio Paz consiste en haber realizado una crítica radical del poder político, señalando sobre todo el aspecto elitista del mismo. En lugar de basarse en una deliberación pública y razonable, la política en América Latina se distinguiría hasta hoy por ser un fenómeno de manipulación de consciencias, que tiene lugar en la oscuridad e imprecisión impuestas por dirigencias privilegiadas, lo que se puede observar claramente en movimientos populistas y partidos socialistas. La falta de una dimensión crítica sería, según Paz, uno de los mayores problemas de América Latina, pues esta región habría nacido con el espíritu de cruzada, la Contrarreforma, el Estado absolutista, el centralismo absorbente y la fusión entre lo religioso y lo político, es decir, de espaldas a la modernidad, a la Ilustración y al pensamiento liberal-democrático (Paz, 1983: 144-152, 163-164).

La obra de Octavio Paz es notable porque pone en cuestionamiento el carácter paradigmático y las pretendidas bondades de los centros metropolitanos. La originalidad teórica de este autor estriba en haber dirigido su impulso crítico a dudar de que el modelo civilizatorio del Norte industrializado -en todas sus variantes- deba ser imitado en el Tercer Mundo. Los ensayistas de la corriente anti-occidental han censurado los comportamientos de las potencias metropolitanas con respecto a América Latina (la "explotación imperialista"), pero nunca han propuesto metas normativas últimas (modernización, industrialización, Estado racionalmente organizado, alto nivel de vida y consumo, relación con la naturaleza) que sean sustancialmente diferentes a las ya alcanzadas en las potencias metropolitanas. Esto es particularmente evidente en aquellos pensadores de orientación socialista, para quienes el objetivo de la evolución histórica estaba preformado por lo alcanzado en la Unión Soviética o China. Octavio Paz dirigió los dardos de su análisis a la configuración política y cultural del antiguo bloque socialista, mostrando ante todo la modernización superficial de viejos moldes bizantinos y zaristas. Pero más interesante ha sido su crítica del Occidente capitalista, esas sociedades opulentas donde prevalecen la estulticia irradiada por los medios masivos de comunicación, el consumismo grosero, la estética de la chabacanería, el hedonismo sin un eros humano y el nihilismo de la abdicación (Paz, 1983: 286). 
Aquí es conveniente reiterar que la corriente crítica -manifiestamente minoritaria dentro de la ensayística latinoamericana- ha estado contrapuesta a la elaboración de ideologías compensatorias de índole romántica sobre el pasado del Nuevo Mundo y de sistemas teóricos que se dedican a la exculpación de lo propio y a la incriminación de lo ajeno en lo referente a las carencias evolutivas de América Latina. Esta tendencia crítica estudia las consecuencias sociales a largo plazo de la invocación de las emociones nacionales profundas, analizando los anhelos del preconsciente colectivo que se refieren a las metas normativas últimas, aparentemente irrenunciables, que las sociedades se han fijado para dar sentido a sus esfuerzos mancomunados. Los representantes de esta corriente se han preocupado poco por tematizar la problemática del reconocimiento de las sociedades latinoamericanas en el concierto de las naciones, puesto que no postulan un contramodelo, es decir, un paradigma propio y "auténtico" de desarrollo. A la hora de diseñar alternativas este impulso crítico retoma un antiguo y modesto principio de la filosofía clásica: el descubrir lo negativo constituye una pista de lo positivo, sin prefigurar su contenido.

Descontando las mencionadas tendencias críticas, tenemos en el pensamiento latinoamericano algunos dilemas centrales que permanecen vigentes hasta hoy. Las metas normativas de desarrollo que persiguen los movimientos políticos e intelectuales más disímiles en America Latina, expresadas en toda concisión por la ensayística, están referidas, en el fondo, a un espacio geográfico y a un horizonte de expectativas que se han originado y estructurado en el área situada entre Estados Unidos y Europa Occidental (hace pocas décadas se habría añadido la antigua Unión Soviética). Estas últimas metas evolutivas pueden ser descritas así:

1. La construcción de un orden social basado en la modernidad científico-técnica y en el principio de rendimiento y eficacia, lo que engloba una sociedad urbana, industrializada, con alto nivel de vida y consumo y una educación determinada por reglas racionales; y

2. La consecución de un Estado nacional fundamentado en la racionalidad instrumental, con una institucionalidad sólida (lo que engloba también una burocracia altamente eficiente), que sea reconocido y respetado en un plano de igualdad liminar en el concierto de naciones. 
Estas metas históricas de largo plazo son totalmente comprensibles. Pero en última instancia carecen, como afirmó Manfred Mols, de una genuina autonomía de objetivos. ${ }^{15}$ Por ello las sociedades de América Latina -y, en realidad, de todo el Tercer Mundo- intentan reafirmar y consolidar aspectos autóctonos y pautas de comportamiento propias, es decir: prácticas culturales anteriores a las incursiones de la modernidad occidental, para encubrir la adopción de paradigmas evolutivos surgidos en los llamados centros metropolitanos. Esta intención, en la cual la filosofía y las diferentes manifestaciones del pensamiento juegan un rol central, trata de hacer digerible la imitación de un modelo de desarrollo que está intrínsecamente vinculado con las detestables potencias imperialistas. Constituye así el nexo afectivo entre una herencia cultural que se pierde paulatinamente y el futuro que se edifica laboriosamente. Este nexo es de gran importancia política y emotiva porque rescata elementos centrales de la propia identidad y de la infancia histórica de cada sociedad. Y tiene una función de enorme relevancia socio-cultural: sugiere, a veces muy efectivamente, que la nación está construyendo un modelo propio y auténtico de desarrollo, aunque lo propio y lo auténtico se restrinja a ámbitos de actividad que pueden ser hoy calificados como secundarios, entre los cuales se encuentran los estilos políticos, el folklore y la vida familiar e íntima.

Considerando la ensayística latinoamericana como un conjunto muy diverso de concepciones socio-políticas, se puede afirmar que ha tenido desde sus comienzos una tradición consagrada a sopesar críticamente sus propios productos, dando como resultado una herencia cultural con una loable inclinación a la autocorrección y al fomento de un espíritu indagatorio, pero reproduciendo simultáneamente -en la mayoría de sus exponentes- los prejuicios colectivos de un pasado autoritario.

15 Cf. el brillante ensayo que no ha perdido vigencia: Manfred Mols, Zum Problem des westlichen Vorbilds in der neueren Diskussion zur politischen Entwicklung (Sobre el problema del paradigma occidental en la nueva discusión acerca del desarrollo político), en: VERFASSUNG UND RECHT IN ÜBERSEE, vol. 8 (1975), $\mathrm{N}^{\mathrm{o}} 1$, p. 5, 11. 


\section{Conclusiones provisionales}

Aunque las metas normativas de evolución no hayan resultado originales, casi todas las corrientes de pensamiento en América Latina consideran la consecución de la modernidad - según moldes metropolitanos- como el camino idóneo de todo progreso histórico. La modernización es vista además como la única senda adecuada para obtener el reconocimiento de las otras naciones y sociedades en un plano de igualdad. La modernidad occidental adopta, sin embargo, un status básicamente ambiguo: es anhelada por dilatados sectores sociales y obviamente por las élites, pero al mismo tiempo es rechazada como extraña y hasta adversa con respecto a la identidad profunda de los pueblos latinoamericanos. Esta ambivalencia tiene que ver con el hecho de que el orden social moderno, fundamentado en el despliegue de la ciencia y la tecnología, por un lado, y la democracia pluralista, por otro, no constituyen realidades que se hayan originado de forma autónoma en América Latina. La construcción de la consciencia nacional permanece confrontada con los modernos valores de orientación que son apreciados positivamente $\mathrm{y}$, al mismo tiempo, rechazados como foráneos de parte de amplios sectores sociales. La aparición periódica de regímenes populistas y el florecimiento intermitente de ideologías nacionalistas e indigenistas son muestras de esa ambivalencia liminar.

En muchos países del Nuevo Mundo el resultado global puede ser calificado como una modernización imitativa que, en el campo político y en el terreno de las pautas recurrentes de comportamiento, convive desde un comienzo con una tradición autoritaria. No hay duda, y esto es también lo curioso, de que se han generado formas muy estables de simbiosis entre este legado autoritario y la modernidad técnico-económica.

La falta de reconocimiento - un fenómeno difícil de medir y hasta de describir convenientemente- promueve modelos políticos e intelectuales que a menudo denotan un regreso a raíces históricas y a herencias prerracionales que no siempre son favorables al Estado de derecho y a la democracia pluralista. En el mundo andino, por ejemplo, tendencias modernizadoras y prooccidentales se hallan enfrentadas a programas que pretenden el retorno a un ámbito premoderno idealizado, a una Edad de Oro de solidaridad inmediata 
y permanente, que no sufriría las alienaciones contemporáneas y las complejidades de la vida actual. Estas últimas son consideradas como posibilidades de corrupción y engaño y como una complicación innecesaria de vínculos humanos que deberían ser directos y comprensibles, como los que se dan en los regímenes paternalistas del populismo latinoamericano. Se trata, probablemente, de ideologías compensatorias que creen ver la solución de estos dilemas en el retorno a elementos irracional-románticos de vieja data como el populismo (Zakaria, 2003). A la larga estos modelos y estas ideologías impiden el desarrollo de la democracia liberal pluralista de corte occidental, la cual, frente a la amplia experiencia histórica de las últimas décadas, ha demostrado ser el mal menor en la esfera de la construcción de modelos de convivencia razonable de los seres humanos. En efecto: la seguridad jurídica, la igualdad ante la ley, la separación de poderes y la protección de los derechos civiles representan elementos y valores irrenunciables en la compleja vida social de la actualidad, y ellos no han sido factores constituyentes ni de las herencias precolombinas, ni de las tradiciones ibero-católicas y tampoco de la praxis populista contemporánea. La dignidad rescatable del orden moderno se halla en aquella concepción de la política que la define como una deliberación permanente y una búsqueda incesante de soluciones racionales y razonables de carácter provisional; esa dignidad se complementa con un interés emancipatorio que está por encima de los valores particulares, por más enraizados que estos se encuentren en tradiciones venerables compartidas por dilatados sectores populares.

\section{Bibliografía}

ALAMÁN, Lucas

1963 Semblanzas e ideario. México. UNAM.

ALBERDI, Juan Bautista

1979 Bases y puntos de partida para la organización política de la República Argentina [1852]. Buenos Aires. CEAL.

BASTIDE, Roger

1973 El prójimo y el extraño. El encuentro de las civilizaciones. Buenos Aires. Amorrortu. 
BAYERTZ, Kurt (comp.)

1998 Solidarität. Begriff und Problem (Solidaridad. Concepto y problema). Frankfurt. Suhrkamp.

BENEDETTI, Mario

1984 El desexilio y otras conjeturas. Madrid. El País.

BERGEL, Martín

2011 El anti-antinorteamericanismo en América Latina (1898-1930). Nueva Sociedad. Buenos Aires. $\mathrm{N}^{\circ} 236$. noviembre-diciembre.

BOHÓRQUEZ, Carmen L.

2004 “Caudillismo y modernidad en Laureano Vallenilla Lanz". Hugo Cancino (comp.). Los intelectuales latinoamericanos entre la modernidad y la tradición, siglos $X I X$ y $X X$. Madrid/Frankfurt. Iberoamericana/Vervuert.

BRUNNER, José Joaquín

1987 "Los debates sobre la modernidad y el futuro de América Latina". Gonzalo Martner (comp.). Diseños para el cambio. Modelos socio-culturales. Caracas. Nueva Sociedad/UNITAR.

CRISTOFFANINI, Pablo Rolando R.

2004 "Mario Vargas Llosa y el nuevo discurso de las élites latinoamericanas". Hugo Cancino (comp.). Los intelectuales latinoamericanos entre la modernidad y la tradición, siglos XIX y XX. Madrid/Frankfurt. Iberoamericana/Vervuert.

DE DIEGO, José Luis

2001 ¿Quién de nosotros escribirá El Facundo? Intelectuales y escritores en Argentina (1970-1986). La Plata. Ediciones al Margen.

DE GANDÍA, Enrique

1948 “Historia de América”. H. G. Wells. Esquema de la historia universal. Buenos Aires. Anaconda.

FERNÁNDEZ RETAMAR, Roberto

1976a "Nuestra América y Occidente". Casa de las Américas. La Habana. Vol. 17. $\mathrm{N}^{\circ} 98$.

1976b Para el perfil definitivo del hombre. La Habana. Letras Cubanas.

1976c "Contra la Leyenda Negra”. Casa de las Américas. La Habana. Vol. 17. No 99.

1989 “Algunos usos de civilización y barbarie". Revista Mexicana de Sociología (México). Vol. LI. No 3. julio-septiembre.

GANDLER, Stefan

2007 Marxismo crítico en México: Adolfo Sánchez Vázquez y Bolívar Echeverría. México. FCE/UNAM. 
GALASSO, Norberto

1973 Manuel Ugarte. Buenos Aires. EUDEBA (dos volúmenes).

GALEANO, Eduardo

1975 Las venas abiertas de América Latina. Buenos Aires. Siglo XXI.

GILMAN, Claudia

2003 Entre la pluma y el fusil: debates y dilemas del escritor revolucionario en América Latina. Buenos Aires. Siglo XXI.

GOEBEL, Michael

2006 "Marxism and the Revision of Argentine History in the 1960s", Estudios Interdisciplinarios de América Latina y El Caribe. Vol. 17. № 1. enerojunio.

HERNÁNDEZ ARREGUI, Juan José

1960 La formación de la conciencia nacional 1930-1960. Buenos Aires. Hachea. JORRÍN Miguel, Martz, John D. (comps.)

1970 Latin-American Political Thought and Ideology. Chapel Hill. North Carolina U.P.

MARCHESI, Aldo

2006 "Imaginación política del anti-imperialismo: intelectuales y política en el Cono Sur a fines de los sesenta". Estudios Interdisciplinarios de América Latina y El Caribe. Vol. 17. № 1. enero-junio.

MELOTTI, Umberto

1974 Marx y el Tercer Mundo. Buenos Aires. Amorrortu.

MÉNDEZ REYES, Salvador

1996 El hispanismo de Lucas Alamán (1792-1853). Toluca. UAEM.

MOLINA, Fernando

2011 René Zavaleta. La etapa nacionalista. La Paz. Gente Común.

MOLS, Manfred

1975 Zum Problem des westlichen Vorbilds in der neueren Diskussion zur politischen Entwicklung (Sobre el problema del paradigma occidental en la nueva discusión acerca del desarrollo político). Verfassung Und Recht In Übersee. Vol. 8. $\mathrm{N}^{\mathrm{o}} 1$.

2011 "Bemerkungen zur Identität Lateinamerikas" (Observaciones sobre la identidad de América Latina). Michael Riekenberg et al. (comps.). KulturDiskurs: Kontinuität und Wandel der Diskussion um Identitäten in Lateinamerika im 19. und 20. Jahrhundert (Discurso de la cultura: continuidad y cambio de la discusión sobre identidades en América Latina en los siglos XIX y XX). Stuttgart. Akademischer Verlag Heinz. 


\section{MORALES BENÍTEZ, Otto}

2011 "La identidad: el mestizaje indoamericano y la universalidad". Michael Riekenberg et al. (comps.). Kultur-Diskurs: Kontinuität und Wandel der Diskussion um Identitäten in Lateinamerika im 19. und 20. Jahrhundert (Discurso de la cultura: continuidad y cambio de la discusión sobre identidades en América Latina en los siglos XIX y XX). Stuttgart. Akademischer Verlag Heinz.

MORSE, Richard M

1982 El espejo de Próspero. Un estudio de la dialéctica del Nuevo Mundo. México. Siglo XXI.

RAMOS, Jorge Abelardo

1985 Introducción a la América criolla. Buenos Aires.

RODÓ, José Enrique

1968 Ariel [1900]. México. Porrúa.

RIBEIRO, Darcy

1986 A patria grande. Río de Janeiro. Guanabara.

PACKENHAM, Robert

1992 The Dependency Movement: Scholarship and Politics in Development Studies. Cambridge. Harvard U. P.

PAZ, Octavio

1950 El laberinto de la soledad. México. Fondo de Cultura Económica.

1976 Posdata, México. Siglo XXI.

1981 El ogro filantrópico. Barcelona. Seix Barral.

1983 Tiempo nublado. Barcelona. Seix Barral.

1985 "Inventar la democracia: América Central y México". Octavio Paz. Pasión crítica. Barcelona. Seix Barral.

\section{PIPES, Richard}

1984 Russland vor der Revolution. Staat und Gesellschaft im Zarenreich (Rusia antes de la revolución. Estado y sociedad bajo el imperio de los zares). Munich.

\section{RANGEL, Carlos}

1977 Del buen salvaje al buen revolucionario. Caracas. Monte Ávila.

1982 El tercermundismo. Caracas. Monte Ávila.

1988 Marx y los socialistas reales. Caracas. Monte Ávila.

SANJINÉS C, Javier

2005 El espejismo del mestizaje. La Paz. IFEA/PIEB.

SARMIENTO, Domingo Faustino

1970 Facundo. Civilización y barbarie [1845]. Madrid. Alianza. 
SIGAL, Silvia

2002 Intelectuales y poder en Argentina: la década del sesenta. Buenos Aires. Siglo XXI.

STABB, Martin S.

1969 América Latina en busca de una identidad. Modelos de ensayo ideológico hispanoamericano 1890-1960. Caracas. Monte Ávila.

SVAMPA, Maristella

1994 El dilema argentino: civilización o barbarie. De Sarmiento al revisionismo peronista, Buenos Aires. El Cielo por Asalto.

TERÁN Oscar

1993 Nuestros años sesentas. La formación de la nueva izquierda intelectual argentina. Buenos Aires. El Cielo por Asalto.

UGARTE, Manuel

1922 La patria grande. Madrid. Editorial Internacional.

ZAKARIA, Fareed

2003 The Future of Freedom: Illiberal Democracy at Home and Abroad. New York. Norton.

ZANATTA, Loris

2008 "El populismo, entre religión y política. Sobre las raíces históricas del antiliberalismo en América Latina". Estudios Interdisciplinarios de América Latina y El Caribe. (Tel Aviv). Vol. 19, № 2, julio-diciembre.

ZEA, Leopoldo

1978 Filosofia de la historia americana. México. FCE.

1988 Discurso desde la marginación y la barbarie. Barcelona. Anthropos.

ZERMEÑO, Guillermo

2004 "La historia, una ciencia de Estado. Notas sobre la función social del historiador en México en el siglo XIX”. Hugo Cancino (comp.). Los intelectuales latinoamericanos entre la modernidad y la tradición, siglos XIX y XX. Madrid/Frankfurt: Iberoamericana/Vervuert.

Recepción 29 de octubre de 2012 y Aceptación 2 de mayo de 2013. 